\title{
Impacto do Arachis pintoi cv. Belmonte sobre a resposta do Axonopus catharinensis ao sombreamento
}

\author{
Gustavo Krahl'1, Rodrigo Luiz Bortoli Zanini ${ }^{2}$, Mateus Ferretto ${ }^{2}$, Patrícia Bresciani Giusti ${ }^{3}$ e Liliane Todeschini ${ }^{4}$
}

\begin{abstract}
Resumo - Este trabalho objetivou definir o impacto da presença de amendoim-forrageiro (Arachis pintoi cv. Belmonte) na resposta da missioneira-gigante (catharinensis Valls) ao sombreamento. $\mathrm{O}$ trabalho foi realizado em Campos Novos, Santa Catarina, e foram testados quatro níveis de sombreamento artificial (0, 25, 50 e 75\%) combinados com dois sistemas de cultivo (missioneira-gigante em monocultivo ou em consórcio com amendoim-forrageiro). As avaliações através de cortes sucessivos ocorreram nos períodos de novembro de 2019 a julho de 2020 e de novembro de 2020 a julho de 2021. Foram avaliados a densidade de perfilhos, o comprimento de colmo e de pseudocolmo, o comprimento do perfilho estendido, o comprimento de folha, o estrato de folha livre de bainha, as clorofilas $a, b$ e total, a produção de forragem e a relação folha: colmo, a área média de folhas por perfilho, o número de folhas por perfilho e a área média das folhas. O consórcio com o amendoim-forrageiro não contribuiu com as respostas da missioneira-gigante ao sombreamento artificial. A gramínea reduziu a produção de forragem e apresentou alterações estruturais significativas apenas sob sombreamento intenso.
\end{abstract}

Termos para indexação: Arachis pintoi; Axonopus catharinensis; Sistemas integrados de produção agropecuária (SIPA).

\section{Impact of Arachis pintoi cv. Belmonte on the response of Axonopus catharinensis to shade conditions}

\begin{abstract}
This study aimed to define the impact of forage peanut (Arachis pintoi cv. Belmonte) on the response of giant missionary grass (Axonopus catharinensis) to shade conditions. To this end, four levels of artificial shading $(0,25,50$ and $75 \%)$ were tested in two cultivation systems (giant missionary grass in monoculture or intercropped with peanut forage) in Campos Novos, SC. Evaluations from successive cuts were performed from 2019 to jul.2020 and from nov.2020 to jul.2021, considering the following variables: tiller density; stem and pseudostem length; extended tiller length; leaf length; sheath-free leaf stratum; chlorophyll $\mathrm{a}, \mathrm{b}$ and total; herbage production; leaf: stem ratio; average leaf area per tiller; number of leaves per tiller; and average leaf area. Intercropping with forage peanuts had no effect on the responses of giant missionary grass to artificial shading. Under intense shading, giant missionary grass showed significant structural changes and reduced herbage production.
\end{abstract}

Index terms: Arachis pintoi; Axonopus catharinensis; Integrated Crop-Livestock Systems (ICLS).

\section{Introdução}

Em busca de alternativas sustentáveis para as propriedades rurais e visando à otimização dos recursos disponíveis, diversas modalidades de sistemas integrados de produção agropecuária (SIPA) são passíveis de implantação. Uma delas consiste na inserção do componente arbóreo em sistemas de produção pecuária. Entretanto, o sombreamento promovido pelas árvores pode afetar a quantidade e a qualidade de forragem produzida, bem como as respostas estruturais do pasto (SOARES et al., 2009).
A missioneira-gigante (Axonopus catharinensis Valls) é uma espécie forrageira perene tropical que apresentou resultados positivos em sistemas sombreados e boa capacidade de consórcio com leguminosas, entre elas o amendoim-forrageiro (Arachis pintoi) (JOCHIMS et al., 2015). Esta leguminosa também apresenta boa adaptação, produtividade e persistência em ambientes sombreados (CRUZ et al., 2020).

De acordo com Barbero et al. (2009), o amendoim-forrageiro consorciado com gramíneas pode contribuir com o aporte de nitrogênio para o sistema, via fixação biológica. O nitrogênio fixa- do é transferido para a leguminosa e disponibilizado ao solo pelo desprendimento dos nódulos e por reciclagem via mineralização da liteira da leguminosa, com possibilidade de ser utilizado pela gramínea. No entanto, o sistema de consorciação entre gramíneas e leguminosas é naturalmente complexo e o sombreamento aumenta esta complexidade com a condução da pastagem ao longo do tempo, o que pode dificultar a manutenção de participação adequada da leguminosa. A introdução de uma leguminosa forrageira em pastos de gramíneas é uma solução adequada para inúmeros problemas produtivos

Recebido em 26/7/2021. Aceito para publicação em 10/11/2021.

http://dx.doi.org/10.52945/rac.v34i3.1255

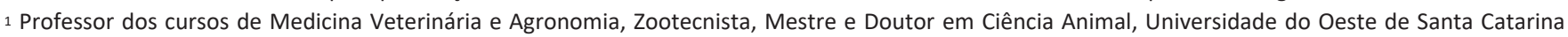
- UNOESC, SC 135, km 180, n²500, Campos Novos, SC, 89620-000, fone: (49) 999791907, e-mail: gustavo.krahl@unoesc.edu.br

${ }^{2}$ Bolsista de Pesquisa do Programa de Bolsas Universitárias de Santa Catarina - UNIEDU (Art. 170).

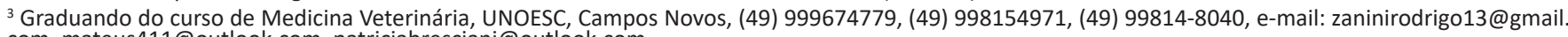
com, mateus411@outlook.com, patriciabresciani@outlook.com.

${ }^{4}$ Graduada do curso de Agronomia, UNOESC, Campos Novos, (49) 988316594, e-mail: Iilitodeschini@hotmail.com. 
e ambientais (ANDRADE et al., 2016). Porém, a adoção tem sido muito baixa, pois as leguminosas não têm persistido no pasto (BODDEY et al., 2020). Neste contexto, objetivou-se definir o impacto de diferentes níveis de sombreamento artificial na produção e na estrutura de dosséis forrageiros compostos por missioneira-gigante em monocultivo ou em consórcio com amendoim-forrageiro, sob a hipótese de que a presença da leguminosa influencia positivamente a resposta da gramínea ao sombreamento.

\section{Material e métodos}

O experimento foi conduzido no município de Campos Novos, Santa Catarina, localizado a $27^{\circ} 22^{\prime} 12^{\prime \prime} \mathrm{S}$ e $51^{\circ}$ $12^{\prime} 15^{\prime \prime} \mathrm{W}$, com altitude de $963 \mathrm{~m}$ e tipo climático Cfb (Köppen). O delineamento experimental utilizado foi o inteiramente casualizado, em esquema fatorial $4 \mathrm{x}$ 2 , sendo quatro níveis de sombreamento artificial (0, 25, 50 e $75 \%)$ combinados com dois sistemas de cultivo (missioneira-gigante em monocultivo ou em consórcio com amendoim-forrageiro). Para cada par foram realizadas três repetições, totalizando 24 unidades experimentais.

Os níveis de sombreamento foram obtidos com a utilização de estruturas construídas em madeira, com tábuas de $15 \mathrm{~cm}$ de largura espaçadas em $45 \mathrm{~cm}$ para o nível de $25 \%$ de sombra, $15 \mathrm{~cm}$ para o nível de $50 \%$ de sombra e $5 \mathrm{~cm}$ para o nível de $75 \%$ de sombra, localizadas $30 \mathrm{~cm}$ acima do dossel forrageiro, que forneceu um regime de luz bimodal para representar o sistema integrado com presença de componente arbóreo, conforme adaptação de Varella et al. (2011).

As mudas de missioneira-gigante (Axonopus catharinensis Valls) (MG) e amendoim-forrageiro (Arachis pintoi cv. Belmonte) (AM) foram implantadas no dia 11 de dezembro de 2018 em caixas de madeira $(0,7 \times 0,3 \times 0,4 \mathrm{~m})$, com substrato de areia e vermiculita $(1: 1, v / v)$, já submetidas ao sombreamento artificial. Durante o estabelecimento das culturas e o regime de cortes, as unidades experimentais foram irrigadas três vezes por semana com lâmina d’água média de $4 \mathrm{~mm}$ diários, com solução nutritiva completa durante todo o período experimental $\left(1,9 \mathrm{~mol} \mathrm{~m}^{-3} \mathrm{KNO}_{3}, 0,55 \mathrm{~mol} \mathrm{~m}^{-3}\right.$ $\mathrm{Ca}\left(\mathrm{NO}_{3}\right)_{2}, 2,5 \mathrm{~mol} \mathrm{~m} \mathrm{~m}^{-3} \mathrm{NH}_{4} \mathrm{NO}_{3}, 0,5 \mathrm{~mol}$ $\mathrm{m}^{-3} \mathrm{CaCl}_{2}, 0,1 \mathrm{~mol} \mathrm{~m}^{-3} \mathrm{NaCl}, 0,5 \mathrm{~mol} \mathrm{~m}^{-3}$ $\mathrm{MgSO}_{4}, 0,4 \mathrm{~mol} \mathrm{~m}^{-3} \mathrm{KH}_{2} \mathrm{PO}_{4}, 25 \times 10$ ${ }^{3} \mathrm{~mol} \mathrm{~m}^{-3} \mathrm{H}_{3} \mathrm{BO}_{3}, 2 \times 10^{-} \mathrm{mol} \mathrm{m}^{-3} \mathrm{MnSO}_{4^{\prime}}$ $2 \times 10^{-3} \mathrm{~mol} \mathrm{~m}^{-3} \mathrm{ZnSO}_{4^{\prime}} 0,5 \times 10^{-3} \mathrm{~mol} \mathrm{~m}^{-3}$ CuSO4, $0,5 \times 10^{-3} \mathrm{~mol} \mathrm{~m}^{-3} \mathrm{H}_{2} \mathrm{MoO}_{4}$ e 20 $\times 10^{-3} \mathrm{~mol} \mathrm{~m}^{-3} \mathrm{Fe}$-HEDTA). Durante o final do outono e do inverno, a irrigação foi reduzida para uma vez na semana, com consequente redução da quantidade de água e nutrientes para um terço do aplicado nos períodos de estabelecimento e coleta efetiva. Não foi realizado nenhum tratamento fitossanitário no período experimental.

A primeira avaliação foi realizada após 90 dias do estabelecimento das culturas (março de 2019), com um corte de uniformização rente ao solo em que foi avaliada a proporção das culturas na massa colhida e a relação folha: colmo da missioneira-gigante. Previamente ao corte foram avaliados os teores de clorofila $a, b$ e total das folhas de missioneira-gigante. No momento do corte, o dossel forrageiro apresentava altura média de $12,2 \mathrm{~cm}$. As avaliações através de cortes sucessivos ocorreram nos períodos de 13 de novembro de 2019 a 2 de julho de 2020 (safra 2019/2020) e de 23 de novembro de 2020 a 13 de juIho de 2021 (safra 2020/2021). Os cortes foram realizados quando o dossel forrageiro atingia $30 \mathrm{~cm}$ de altura, com aplicação de rebaixamento de $50 \%$ em relação à altura inicial.

Previamente a cada corte nas safras de 2019/2020 e 2020/2021, foi avaliada a densidade de perfilhos em área de $0,06 \mathrm{~m}^{2}$. Os comprimentos de perfilho estendido (PE), de colmo e pseudocolmo foram medidos com régua do nível do solo até o ápice da folha mais comprida e até a última lígula exposta, respectivamente. A partir destas medidas, foi calculado o estrato de folha livre de bainha (EFLB), como a diferença entre a altura do perfilho estendido e do colmo e do pseudocolmo, em proporção relativa ao perfilho estendido. Amostras da parte aérea da missioneira-gigante foram coletadas em área de $0,06 \mathrm{~m}^{2}$ e foram fracionadas em lâminas foliares, colmos, pseudocolmos e material senescente. As frações foram secas em es- tufa de ventilação forçada a $60^{\circ} \mathrm{C}$ por 72 horas para posterior pesagem e determinação da produção de forragem e da relação folha: colmo (F: C). As plantas de amendoim-forrageiro foram coletadas e secadas em estufa de circulação forçada a $60^{\circ} \mathrm{C}$, por 72 horas, para posterior pesagem e determinação da produção total de forragem. Ao final de cada período de avaliação por cortes sucessivos, todas as parcelas foram cortadas rente ao solo e as amostras foram secadas em estufa de circulação forçada a $60^{\circ} \mathrm{C}$ por 72 horas, para a determinação da proporção final de cada cultura quando em consórcio. As medidas indiretas dos teores de clorofila $a, b$ e total das folhas da missioneira-gigante foram realizadas com clorofilômetro (ClorofiLOG CFL 1030 - Falker ${ }^{\circledast}$ ) imediatamente antes de cada corte.

Os dados foram submetidos ao teste de normalidade dos resíduos (ShapiroWilk) e à análise de variância. Quando houve efeito significativo dos fatores ou interação entre fatores, os dados foram submetidos ao teste de médias (Tukey), considerando 5\% de significância. Para as variáveis coletadas durante o período de cortes sucessivos, o ano de avaliação foi considerado como fator para a densidade de perfilhos, a produção de forragem de missioneira-gigante, a produção total de forragem e a proporção de amendoim-forrageiro na forragem produzida. As variáveis relacionadas às respostas em perfilhos individuais foram coletadas apenas no primeiro período de cortes sucessivos (safra 2019/2020). Todas as análises foram realizadas utilizando o software R versão 3.6.2 (R Development Core Team, 2019).

\section{Resultados e discussão}

No ano de 2019 foi realizado apenas o corte de uniformização, 90 dias após a implantação das mudas. Em relação às safras $2019 / 2020$ e $2020 / 2021$, foram realizados em média 4,9 e 4,3 cortes, com período de utilização de 119 e 137 dias e intervalo entre cortes médio de 31 e 43 dias, respectivamente.

Houve interação entre níveis de sombreamento e ano de avaliação para as variáveis densidade de perfilhos de missioneira-gigante $(P=0,002)$, produ- 
ção de forragem de missioneira-gigante $(P=0,002)$ e produção total de forragem $(P=0,002)$ (Figura 1$)$. Não houve interação entre níveis de sombreamento e sistema de cultivo para as outras variáveis avaliadas $(P>0,05)$. A densidade de perfilhos de missioneira-gigante reduziu-se a partir de $25 \%$ de sombreamento no primeiro ano, e no segundo ano não foi observada alteração em relação aos níveis de sombreamento (Figura 1A). A redução da população de perfilhos é uma resposta clássica de plantas na sombra (OLIVEIRA et al., 2020). Além disso, dois fatores podem ter contribuído para a redução dos perfilhos entre o primeiro e o segundo ano de avaliação: o corte de uniformização rente ao solo, realizado no outono de 2019 , e a irrigação com a solução nutritiva, feita com menor frequência durante o período de inverno.

A produção de forragem de missioneira-gigante (Figura 1B) e a produção total de forragem (Figura $1 \mathrm{C}$ ) na safra 2019/2020 foram coerentes com a densidade de perfilhos e com a produção de forragem consistente até $25 \%$ de sombreamento. Na safra 2020/2021, a produção de missioneira-gigante e consequentemente produção total foram consistentes até $50 \%$ de sombreamento. Embora com irrigação média de $4 \mathrm{~mm} / \mathrm{dia}$, no período de fevereiro a abril choveu apenas $59 \%$ da quantidade observada para o mesmo período no primeiro ano de avaliação (INMET, 2021). Pachas et al. (2014) observaram aumento da produção de matéria seca da missioneira-gigante sob sombra moderada (38\%) quando comparado ao pleno sol e níveis mais intensos de sombreamento, atribuindo a maior produção de forragem ao menor estresse hídrico pela manutenção da umidade do solo e maior disponibilidade de nutrientes, principalmente o nitrogênio. Cruz et al. (2020) observaram que o amendoimforrageiro, sob sombreamento de $30 \%$, apresentou rendimento superior ao de quando estava sob pleno sol.

Observou-se que na primeira coleta, realizada no início de 2019, a proporção de amendoim-forrageiro na massa colhida foi de $42,8 \%$ (calculada a partir da Tabela 1). Isso resultou em maiores teores de clorofila $a, b$ e total, além de incremento na relação folha: colmo da missioneira-gigante quando em consór-
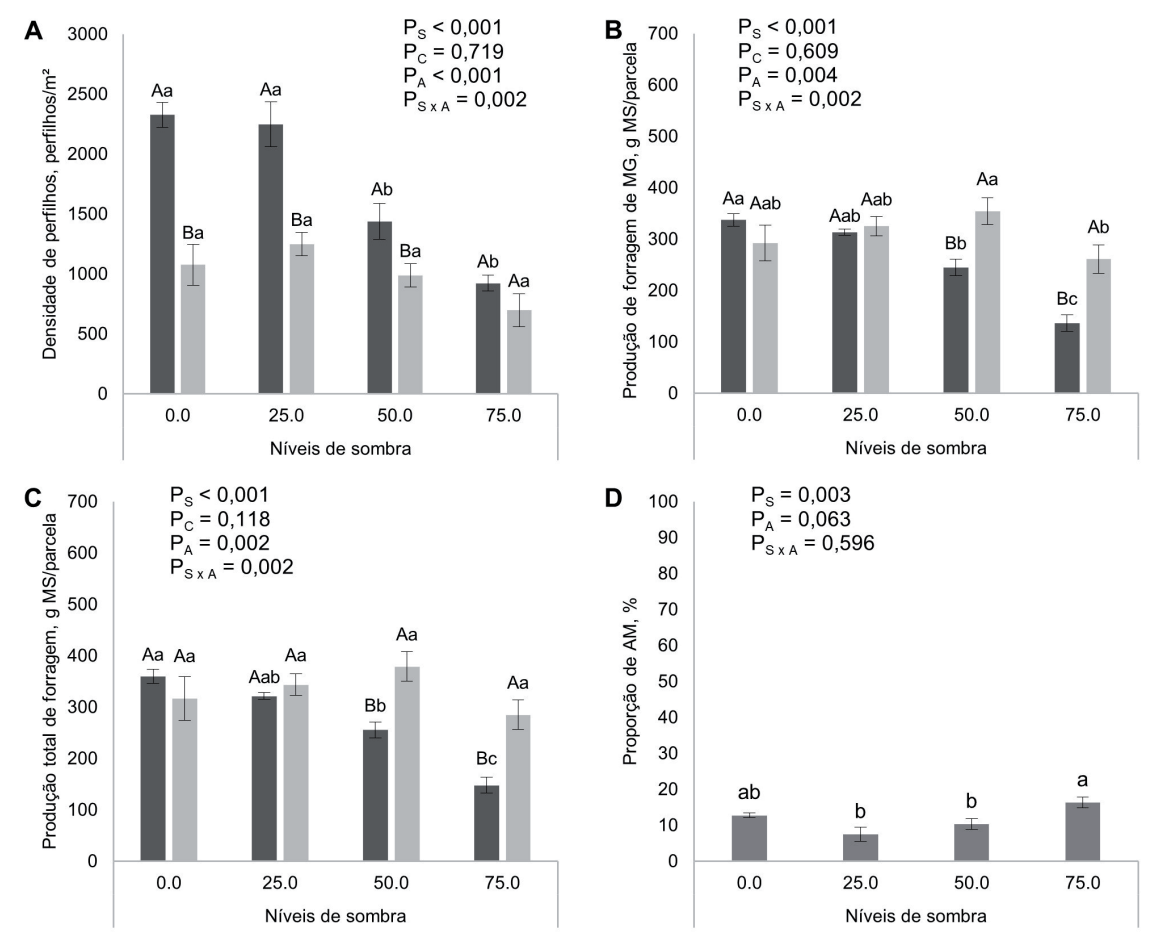

Figura 1. Resultado da interação entre níveis de sombreamento e ano $\left({ }_{S \times A}\right)$ ou efeitos individuais para sombreamento $\left({ }_{S}\right)$, sistema de cultivo $\left({ }_{C}\right)$ e ano $\left({ }_{A}\right)$ para densidade de perfilhos de missioneira-gigante $(A)$; produção de forragem de missioneira-gigante $(B)$; produção total de forragem (C); e proporção de amendoim-forrageiro na forragem produzida (D) em função de níveis de sombreamento (\%) em dois anos de avaliação. Quando houve interação entre sombreamento e ano, as barras escuras representam o ano 1 de coletas sucessivas (safra 2019/2020) e barras claras representam o ano 2 de coletas sucessivas (safra 2020/2021). Em caso de interação, barras contendo mesmas letras maiúsculas não diferem para ano de cultivo. Barras contendo mesmas letras minúsculas não diferem para os níveis de sombreamento.

Figure 1. Result of the interaction between shading levels and year $\left(_{S \times A}\right)$ or individual effects for shading $\left({ }_{S}\right)$, cropping system $\left(C_{C}\right)$ and year $\left({ }_{A}\right)$ for tiller density of giant missionary grass $(A)$; herbage production of giant missionary grass (B); total herbage production (C); and proportion of peanut in the herbage produced (D) as a function of shading levels (\%) in two years of evaluation. When there was an interaction between shading and year, the dark gray bars represent year 1 of successive collections (2019/2020 harvest) and light gray bars represent year 2 of successive collections (2020/2021 harvest). In case of interaction, bars containing the same uppercase letters did not differ for year of cultivation. Bars containing same lowercase letters did not differ for shading levels.

cio com o amendoim-forrageiro (Tabela 2).

A utilização de leguminosas consorciadas com gramíneas pode contribuir com o aporte de nitrogênio para o sistema, via fixação biológica (BARBERO et al., 2009). Logo, a maior disponibilização de nitrogênio no solo pode favorecer a síntese de moléculas de clorofila (LOPES et al., 2017) e melhorar o aproveitamento da luz em ambientes sombreados (OLIVEIRA et al., 2013), em especial da clorofila $b$ (ZHU et al., 2017).

No entanto, nas coletas ao final dos períodos de 2019/2020 e 2020/2021, as proporções de amendoim-forrageiro na massa colhida foram de 8,8 e $14,2 \%$, respectivamente (calculado a partir da Tabela 1). Pode-se observar também a baixa proporção média de amendoimforrageiro na massa colhida acima do resíduo estabelecido através do regime sucessivo de cortes $(11,8 \%$, conforme a Figura 1D). De acordo com Cadisch et al. (1994), a proporção de leguminosas em pastos consorciados deve situarse entre 20 e $40 \%$. Segundo Alonzo et al. (2017), o amendoim-forrageiro não deve ser utilizado sob pastejo intenso, pois modifica a composição morfológica e a massa de forragem acumulada. Jochims et al. (2015), em estudo com o 
Tabela 1. Proporção de missioneira-gigante (MG) e amendoim-forrageiro (AM) na massa de forragem da coleta final, teores de clorofila $a, b$ e total e relação folha colmo de missioneira-gigante submetida a níveis de sombreamento e consórcio com amendoimforrageiro em três momentos (2019; 2019/2020; e 2020/2021)

Table 1. Proportion of giant missionary grass (MG) and forage peanut (AM) in the herbage mass of the final collection, levels of chlorophyll $a, b$ and total leaf: stem ratio of giant missionary grass submitted to shading levels and intercropping with forage peanuts in three moments (2019; 2019/2020; and 2020/2021

\begin{tabular}{|c|c|c|c|c|c|c|}
\hline \multirow{2}{*}{ Variáveis } & \multicolumn{4}{|c|}{ Níveis de sombra (\%) } & \multirow{2}{*}{ EPM $^{1}$} & \multirow{2}{*}{ P-valor } \\
\hline & 0 & 25 & 50 & 75 & & \\
\hline
\end{tabular}

2019

\begin{tabular}{|c|c|c|c|c|c|c|}
\hline $\begin{array}{l}\text { Proporção de MG na } \\
\text { coleta final (\%) }\end{array}$ & $42.6 \mathrm{~b}$ & $53.8 \mathrm{ab}$ & $80.0 \mathrm{a}$ & $52.4 \mathrm{ab}$ & \multirow{2}{*}{5.2} & \multirow{2}{*}{0.035} \\
\hline $\begin{array}{l}\text { Proporção de AM na coleta } \\
\text { final (\%) }\end{array}$ & $57.4 \mathrm{a}$ & $46.2 \mathrm{ab}$ & $20.0 \mathrm{~b}$ & $47.6 \mathrm{ab}$ & & \\
\hline Clorofila a & 30.5 & 29.7 & 30.8 & 31.4 & 0.29 & 0.126 \\
\hline Clorofila $b$ & $16.8 \mathrm{~b}$ & $16.3 \mathrm{~b}$ & $19.8 \mathrm{a}$ & $20.4 \mathrm{a}$ & 0.45 & $<0.001$ \\
\hline Clorofila total & $47.2 \mathrm{ab}$ & $46.0 \mathrm{~b}$ & $50.6 \mathrm{ab}$ & $51.8 \mathrm{a}$ & 0.70 & 0.006 \\
\hline Relação folha: colmo & $0.64 \mathrm{~b}$ & $0.63 b$ & $0.69 \mathrm{~b}$ & $1.13 \mathrm{a}$ & 0.06 & $<0.001$ \\
\hline \multicolumn{7}{|l|}{$2019 / 2020$} \\
\hline $\begin{array}{l}\text { Proporção de MG na } \\
\text { coleta final (\%) }\end{array}$ & 92.3 & 96.0 & 94.3 & 82.0 & \multirow{2}{*}{2.2} & \multirow{2}{*}{0.083} \\
\hline $\begin{array}{l}\text { Proporção de AM na coleta } \\
\text { final (\%) }\end{array}$ & 7.7 & 4.0 & 5.7 & 18.0 & & \\
\hline Clorofila a & 27.8 & 26.3 & 28.3 & 26.8 & 0.44 & 0.466 \\
\hline Clorofila $b$ & 13.5 & 12.7 & 13.8 & 12.7 & 0.39 & 0.728 \\
\hline Clorofila total & 41.3 & 39.0 & 42.1 & 39.5 & 0.80 & 0.574 \\
\hline Relação folha: colmo & 1.36 & 1.69 & 1.72 & 1.66 & 0.09 & 0.371 \\
\hline
\end{tabular}

$2020 / 2021$

\begin{tabular}{|lcccccc|}
$\begin{array}{l}\text { Proporção de MG na } \\
\text { coleta final (\%) }\end{array}$ & 83.1 & 87.2 & 91.2 & 81.8 & & \\
\hline $\begin{array}{l}\text { Proporção de AM na coleta } \\
\text { final (\%) }\end{array}$ & 16.9 & 12.8 & 8.8 & 18.2 & & 0.228 \\
\hline Clorofila $a$ & 23.3 & 22.3 & 24.5 & 25.6 & 0.55 & 0.204 \\
\hline Clorofila $b$ & 8.7 & 8.2 & 9.5 & 9.8 & 0.28 & 0.245 \\
\hline Clorofila total & 32.0 & 30.5 & 34.0 & 34.8 & 0.80 & 0.282 \\
\hline Relação folha: colmo & 1.78 & 1.84 & 2.05 & 1.85 & 0.05 & 0.233 \\
\hline
\end{tabular}

Médias seguidas com mesma letra na linha não diferem entre si pelo teste de Tukey $(P>0,05) .{ }^{1}$ Erro padrão da média. consórcio de missioneira-gigante com cultivares de amendoim-forrageiro, também observaram redução da participação da leguminosa no terceiro ano de avaliação.

Em relação às respostas nos perfiIhos individuais da missioneira-gigante, mesmo com menor número de folhas por perfilho em sombreamento intenso $(P=0,003)$, houve maior área de folhas por perfilho $(P=0,033)$, principalmente devido à maior área média das folhas $(P=0,002)$ (Tabela 3$)$. Isso resultou no aumento do estrato de folha livre de bainha $(P<0,001)$. Diferentemente das respostas observadas por Baldissera et al. (2016), em que a missioneira-gigante aumentou o comprimento de colmo e pseudocolmo, e o comprimento de folha para melhorar a captação de luz em sistema sombreado (ANDRÉ et al., 2020), neste trabalho foi observado aumento apenas do comprimento das foIhas. $O$ resultado destas respostas foi o aumento no estrato de folha livre de bainha com o aumento do sombreamento. Benvenutti et al. (2016) observaram que pode ocorrer redução drástica na taxa de consumo instantâneo quando os animais acessam o estrato rico em colmos e pseudocolmos. De acordo com Guzatti et al. (2017), a taxa de consumo instantâneo de pastos anuais de clima temperado pode ser impactado quando o estrato de folha livre de bainha for menor que aproximadamente $50 \%$ da altura do perfilho estendido.

\section{Conclusão}

O consórcio com o amendoim-forrageiro não contribuiu com as respostas da missioneira-gigante ao sombreamento artificial.

A missioneira-gigante reduziu a produção de forragem e apresentou alterações estruturais significativas apenas sob sombreamento intenso (75\%).

\section{Agradecimentos}

Ao Programa de Bolsas Universitárias de Santa Catarina - Uniedu, pelas bolsas de estudo concedidas por meio dos editais № 60/UNOESC-R/2019 e № 14/UNOESC-R/2020. 
Tabela 2. Teores de clorofila $a, b$ e total e relação folha: colmo de missioneira-gigante submetida a níveis de sombreamento e consórcio com amendoim-forrageiro em três momentos (2019; 2019/2020; e 2020/2021)

Table 2. Levels of chlorophyll $a, b$ and total leaf: stem ratio of giant missionary grass submitted to shading levels and intercropping with forage peanuts in three moments (2019; 2019/2020; and 2020/2021)

\begin{tabular}{|c|c|c|c|c|}
\hline \multirow{2}{*}{ Variáveis avaliadas } & \multicolumn{2}{|c|}{ Sistema de cultivo } & \multirow{2}{*}{$\mathrm{EPM}^{1}$} & \multirow{2}{*}{ P-valor } \\
\hline & MG & $M G+A M$ & & \\
\hline \multicolumn{5}{|l|}{2019} \\
\hline Clorofila $a$ & $30.0 \mathrm{~b}$ & $31.2 \mathrm{a}$ & 0.29 & 0.013 \\
\hline Clorofila $b$ & $17.4 \mathrm{~b}$ & $19.3 \mathrm{a}$ & 0.45 & 0.022 \\
\hline Clorofila total & $47.3 b$ & $50.5 \mathrm{a}$ & 0.70 & 0.018 \\
\hline Relação folha: colmo & $0.69 \mathrm{~b}$ & $0.86 \mathrm{a}$ & 0.06 & 0.013 \\
\hline \multicolumn{5}{|l|}{$2019 / 2020$} \\
\hline Clorofila $a$ & 27.4 & 27.2 & 0.44 & 0.794 \\
\hline Clorofila $b$ & 13.0 & 13.3 & 0.39 & 0.761 \\
\hline Clorofila total & 40.5 & 40.5 & 0.80 & 0.993 \\
\hline Relação folha: colmo & 1.49 & 1.73 & 0.09 & 0.149 \\
\hline \multicolumn{5}{|l|}{$2020 / 2021$} \\
\hline Clorofila $a$ & 23.9 & 23.9 & 0.55 & 0.956 \\
\hline Clorofila $b$ & 8.9 & 9.2 & 0.28 & 0.673 \\
\hline Clorofila total & 32.6 & 33.0 & 0.80 & 0.835 \\
\hline Relação folha: colmo & 1.88 & 1.87 & 0.05 & 0.924 \\
\hline
\end{tabular}
padrão da média.

Tabela 3. Comprimento do colmo e pseudocolmo, comprimento do perfilho estendido (PE), comprimento de folha, estrato de folha livre de bainha (EFLB), área de folhas por perfilho (AFP), área média das folhas (AMF) e número de folhas por perfilho de missioneira-gigante submetida a níveis de sombreamento e consórcio com amendoim-forrageiro

Table 3. Stem and pseudostem length, extended tiller length, leaf length, sheath-free leaf, leaf area per tiller, average leaf area and number of leaves per tiller of giant missionary grass subjected to levels of shading and intercropping with forage peanut

\begin{tabular}{|c|c|c|c|c|c|c|}
\hline \multirow{2}{*}{ Variáveis } & \multicolumn{4}{|c|}{ Níveis de sombra, \% } & \multirow{2}{*}{$\mathrm{EPM}^{1}$} & \multirow{2}{*}{ P-valor } \\
\hline & 0 & 25 & 50 & 75 & & \\
\hline $\begin{array}{l}\text { Comprimento do } \\
\text { colmo + pseud., cm }\end{array}$ & 18,9 & 20,3 & 20,1 & 20,4 & 0,3 & 0,340 \\
\hline $\begin{array}{l}\text { Comprimento do PE, } \\
\mathrm{cm}\end{array}$ & $38,9 \mathrm{c}$ & $41,1 b$ & $42,3 \mathrm{~b}$ & 49,7 a & 0,9 & $<0,001$ \\
\hline $\begin{array}{l}\text { Comprimento de } \\
\text { folha, } \mathrm{cm}\end{array}$ & $20,0 \mathrm{c}$ & $20,8 \mathrm{bc}$ & $22,2 b$ & 29,3 a & 0,8 & $<0,001$ \\
\hline EFLB, \% & $51,3 \mathrm{~b}$ & $50,6 \mathrm{~b}$ & $52,5 \mathrm{~b}$ & 58,9 a & 0,8 & $<0,001$ \\
\hline AFP, $\mathrm{cm}^{2}$ & $105,1 \mathrm{ab}$ & $118,2 \mathrm{ab}$ & $101,4 \mathrm{~b}$ & 134,4 a & 4,43 & 0,033 \\
\hline $\mathrm{AMF}, \mathrm{cm}^{2}$ & $52,1 \mathrm{~b}$ & $58,6 \mathrm{~b}$ & $59,9 \mathrm{~b}$ & 88,3 a & 3,97 & 0,002 \\
\hline NFP & $6,2 \mathrm{a}$ & $6,1 \mathrm{a}$ & $5,2 a b$ & $4,6 \mathrm{~b}$ & 0,191 & 0,003 \\
\hline
\end{tabular}

Médias seguidas com mesma letra na linha não diferem entre si pelo teste de Tukey $(\mathrm{P}>0,05) .{ }^{1}$ Erro padrão da média.

\section{Referências}

ALONZO, L.A.G.; FERREIRA, O.G.L.; VAZ, R.Z.; COSTA, O.A.D.; MOTTA, J.F.; BRONDANI, W.C. Amendoim-forrageiro manejado com baixos resíduos de pastejo por ovinos. Arquivo Brasileiro de Medicina Veterinária e Zootecnia, Belo Horizonte, v.69, n.1, p.173-180, 2017. DOI: https://doi.org/10.1590/1678-41629157.

ANDRADE, E.A.; ALMEIDA, E.X.; RAUPP, G.T.; MIGUEL, M.F.; DE LIZ, D.M.; CARVALHO, P.C.F.; BAYER, C.; RIBEIRO-FILHO, H.M.N. Herbage intake, methane emissions and animal performance of steers grazing dwarf elephant grass v. dwarf elephant grass and peanut pastures. Animal, Amsterdan, v.10, n.10, p.1684-1688, 2016. DOI: https://doi. org/10.1017/S1751731116000628.

ANDRÉ, T.B.; OLIVEIRA, L.B.T.; SANTOS, A.C. Growth and Development of Mombassa Grass Grown in Full Sun and Shade Under Nitrogen Levels. Revista Engenharia $\mathrm{Na}$ Agricultura - Reveng, Viçosa, v.28, p.11-23, 2020. DOI: https://doi.org/10.13083/reveng.v28i.932.

BARBERO, L.M.; CECATO, U.; BERNARDO LUGÃO, S.M.; GOMES, J.A.N.; LIMÃO, V.A.; BASSO, K.C. Forage production and morphological components of coastcross pasture mixed with peanut forage. Revista Brasileira de Zootecnia, Viçosa, v.38, n.5, p.788-785, 2009. DOI: https://doi.org/10.1590/S151635982009000500002.

BALDISSERA, T.C.; PONTES, L.S.; GIOSTRI, A.F.; BARRO, R.S.; LUSTOSA, S.B.C.; DE MORAES, A.; CARVALHO, P.C.F. Sward structure and relationship between canopy height and light interception for tropical C4 grasses growing under trees. Crop and Pasture Science, Camberra, v.67, n.11, p.1199-1207, 2016. DOI: https://doi.org/10.1071/CP16067.

BENVENUTTI, M.A.; PAVETTI, D.R.; POPPI, D.P.; GORDON, I.J.; CANGIANO, C.A. Defoliation patterns and their implications for the management of vegetative tropical pastures to control intake and diet quality by cattle. Grass and Forage Science, Hoboken, v.71, n.3, p.424-436, 2016. DOI: https://doi. org/10.1111/gfs.12186.

BODDEY, R.M.; CASAGRANDE, D.R.; HOMEM, B.G.C.; ALVES, B.J.R. Forage legumes in grass pastures in tropical Brazil and like- 
ly impacts on greenhouse gas emissions: A review. Grass and Forage Science, Hoboken, v.75, n.4, p.357-371, 2020. DOI: https://doi. org/10.1111/gfs.12498.

CADISCH, G.; SCHUNKE, R.M.; GILLER, K.E. Nitrogen cycling in a pure grass pasture and a grass legume mixture on a red latosol in Brazil. Tropical Grasslands, Cali, v.28, p.4352, 1994.

CRUZ, P.J.R.; SANTOS, M.V.; SILVA, L.D.; FERREIRA, E.A.; MAGALHÃES, M.A.; MARTUSCELLO, J.A.; FONSECA, D.M. Morphogenetic, physiological, and productive of forage peanut responses to shading. Pesquisa Agropecuária Brasileira, Brasília, v.55, e01746, 2020. DOI: https://doi.org/10.1590/s16783921.pab2020.v55.01746.

GUZATTI, G.C.; DUCHINI, P.G.; SBRISSIA, A.F.; MEZZALIRA, J.C.; ALMEIDA, J.G.R.; CARVALHO, P.C.F.; RIBEIRO-FILHO, H.M.N. Changes in the short-term intake rate of herbage by heifers grazing annual grasses throughout the growing season. Grassland Science, Hoboken, v.63, n.4, p.255-264, 2017. DOI: https://doi.org/10.1111/grs.12170.

INMET. Instituto Nacional de Meteorologia: Normais Climatológicas do Brasil. Disponível em: https://portal.inmet.gov.br/dadoshistoricos. Acesso em: 18 nov. 2021.

JOCHIMS, F.; MIRANDA, M.; PORTES, V. M.;
NESI, C. N. Produtividade de missioneira-gigante, amendoim-forrageiro e suas consorciações. Agropecuária Catarinense, Florianópolis, v.28, n.2, p.84-88, 2015.

LOPES, C.M.; PACIULLO, D.S.C.; ARAÚJO, S.A.C.; GOMIDE, C.A.M.; MORENZ, M.J.F.; VILLELA, S.D.J. Massa de forragem, composição morfológica e valor nutritivo de capimbraquiária submetido a níveis de sombreamento e fertilização. Arquivo Brasileiro de Medicina Veterinária e Zootecnia, Belo Horizonte, v.69, n.1, p.225-233, 2017. DOI: https://doi.org/10.1590/1678-4162-9201.

OLIVEIRA F.L.R.; MOTA, V.A.; RAMOS, M.S.; SANTOS, L.D.T.; DE OLIVEIRA, N.J.F.; GERASEEV, L.C. Comportamento de Andropogon gayanus cv. 'planaltina' e Panicum maximum cv. 'tanzânia' sob sombreamento. Ciência Rural, Santa Maria, v.43, p.348-354, 2013. DOI: https://doi.org/10.1590/S010384782013000200026 .

OLIVEIRA, G.L.; OLIVEIRA, M.E.; MACÊDO, E.O.; ANDRADE, A.C.; EDVAN, R.L. Effect of shading and canopy height on pasture of Andropogon gayanus in silvopastoral system. Agroforestry Systems, New York, v.5, 2020. DOI: https://doi.org/10.1007/s10457-01900458-5.

PACHAS, A. N.A.; JACOBO, E. J.; GOLDFARB, M. C.; LACORTE, S. M. Response of Axonopus catarinensis and Arachis pintoi to shade con- ditions. Tropical Grasslands-Forrajes Tropicales, Cali, v.2, n.1, p.111-112, 2014. DOI: https://doi.org/10.17138/tgft(2)111-112.

R Development Core Team. 2019. R: a language and environment for statistical computing. R Foundation for Statistical Computing, Vienna, Austria.

SOARES, A.B.; SARTOR, L.R.; ADAMI, P.F.; VARELLA, A.C.; FONSECA, L.; MEZZALIRA, J.C. Influência da luminosidade no comportamento de onze espécies forrageiras perenes de verão. Revista Brasileira de Zootecnia, Viçosa, v.38, n.3, p.443-451, 2009. DOI: https://doi.org/10.1590/s151635982009000300007.

VARELLA, A.C.; MOOT, D J.; POLLOCK, K.M.; PERI, P.L.; LUCAS, R.J. Do light and alfalfa responses to cloth and slatted shade represent those measured under an agroforestry system? Agroforestry Systems, New York, v.81, n.2, p.157-173, 2011. DOI: https://doi. org/10.1007/s10457-010-9319-6.

ZHU, H.; LI, X.; ZHAI, W.; LIU, Y.; GAO, Q.; LIU, J.; REN, L.; CHEN, H.; ZHU, Y. Effects of low light on photosynthetic properties, antioxidant enzyme activity, and anthocyanin accumulation in purple pak-choi (Brassica campestris ssp. Chinensis Makino). PLoS ONE, San Francisco, v.12, p.1-17, 2017. DOI: https://doi.org/10.1371/journal. pone.0179305.

\section{Não deire sua consciência escorrer pelo ralo: preserve a água e evite o desperdício.}

